\title{
Why nature-based solutions to climate change must be grounded in sound biodiversity science
}

\author{
Nathalie Seddon, Beth Turner, Pam Berry, Alexandre Chausson, and Cécile A.J. Girardin \\ Department of Zoology and Environmental Change Institute, University of Oxford
}

The current focus on afforestation in climate policy runs the risk of compromising both longterm carbon storage and human adaptation. It also works against efforts to stem the tide of biodiversity loss. We outline why an emphasis on diverse, intact natural ecosystems-as opposed to tree plantations with fast-growing exotic species-will help nations deliver the goals of the Paris Agreement and much more.

Keywords: biodiversity, climate change, forests, nature-based solutions, policy, resilience

T he idea that natural ecosystems can help us fight both the drivers and impacts of climate change has been gaining traction over the past few years, including recent emphasis in the IPCC Special Report ${ }^{1}$. In particular, the Paris Climate Change Agreement calls on all Parties to acknowledge "the importance of ensuring the integrity of all ecosystems, including oceans, and the protection of biodiversity, recognized by some cultures as Mother Earth", and $66 \%$ of signatories to the Agreement commit to "green" or "nature-based solutions" in their climate pledges ${ }^{2}$ (Box 1). Such recognition of nature's value, in particular through policies promoting forests as carbon sinks, was hard-won by negotiators and non-state actors and is vitally important. However, we are concerned by aspects of the narrative reaching policy makers and call on scientists studying biodiversity and ecosystem functions and services to fully engage with and inform the process by which high level pledges are translated into on-the-ground actions.

\section{A focus on forests}

When it comes to high level multilateral pledges for nature the current focus is on forests. The Bonn Challenge-launched in by IUCN and Germany in 2011 and currently involving 56 nations-is a global effort to restore 150 million hectares of deforested and degraded land by 2020 and 350 million hectares by 20305; the New York Declaration on Forests -signed in 2014 by 37 governments, 63 NGOs, 53 multinational companies and 16 indigenous community groups - pledges to halve deforestation by 2020 and end it by 20306; and the Trillion Trees Partnership is a new 25-year initiative to restore one trillion trees by 2050 , the number needed to reverse the global decline in tree cover ${ }^{7}$. Such initiatives have inspired a significant number of private companies to voluntarily commit to eradicating deforestation from their supply chain. Added to this, signatories to the Sustainable Development Goals have committed to stop deforestation by 2020 , while the UN's Rio Convention on Biological Diversity also addresses deforestation, both in terms of 
biodiversity and enhancement of carbon stocks.

From a climate perspective, this focus on forest is vitally important. Global $\mathrm{CO}_{2}$ emissions from land use change (mainly deforestation) represented around $12 \%$ of global emissions for 2007-2016, while the terrestrial carbon sink stored around $28 \%$ of emissions (3.0 $\pm 0.8 \mathrm{GtC}$ per year) over the same period $^{8}$. The restoration of 350 million hectares of forest by 2030 (i.e. the Bonn Challenge) would add to this, sequestering up to $1.6 \mathrm{GtC}$ per year, equivalent to $14 \%$ of the global carbon emissions ${ }^{5}$. Because of this powerful role as both a source and a sink for $\mathrm{CO} 2$, forests have long played a key role in the international climate change policy (Box 2) and are increasingly in the limelight.

\section{Monoculture plantations won't help in a rapidly changing world}

The key question is how are these high level pledges for forests translating into action on the ground? Existing international frameworks provide a definition of forests created for the purpose of assessing forest carbon stocks alone and as a result pledges tend to focus more on the extent than the quality of forest to be protected, afforested or reforested ${ }^{2,10}$. Further, the approach encourages the establishment of monoculture plantations of fast growing exotic species. While such plantations may store carbon in the short term, their capacity to do so over the longterm is impaired by changing conditions and disturbances that are becoming more rapid and severe under climate change ${ }^{11}$. For forests to sequester carbon over the long term, they must be able to resist, recover and/or adapt to these changes ${ }^{12}$, and we know with increasing certainty that such functional resilience is strongly determined by ecosystem connectivity, heterogeneity, and diversity at multiple trophic levels ${ }^{13}$. For example, recent experimental studies demonstrate that compared to monocultures, diverse plantations of tropical forest are more resilient to extreme floods and droughts ${ }^{14}$, while mixed species forests are more resistant to pests and disease ${ }^{15}$. Connectivity, meanwhile, is widely viewed as being critical to the adaptive capacity and integrity of intact forests and their biota in the face of environmental change ${ }^{10}$.

Therefore, to enable longterm carbon storage mitigation policy must move away from encouraging single species plantations and instead support practices that enhance the ecological attributes that underpin functional resilience. We are already seeing the evidence that diversity (of species and/or traits) will be key to preserving forests as carbon sinks in the face of climate change ${ }^{16}$.

\section{What about carbon-rich coastal habitats, peatlands and grasslands?}

It is vital that the current emphasis on forests does not detract from other ecosystems, many of which are also very important for storing carbon. A new campaign to raise the profile of natural solutions to climate change advocates that restoring and protecting forest can "deliver $30 \%$ of the climate solution needed by 2030" 17 . Although the campaign strongly emphasises forests, it is based on a study showing that conservation actions in all major natural terrestrial habitats including grasslands, wetlands and agricultural lands could 
help provide up to $30-37 \%$

$\mathrm{CO}_{2}$ mitigation needed through to 2030 for $>66 \%$ chance of keeping warming to $<2{ }^{\circ} \mathrm{C}^{18}$.

Mangroves in particular are one of the planet's greatest carbon storehouses, with $\mathrm{CO}_{2}$ burial rates (i.e. rates at which carbon is converted into biomass through photosynthesis) 20 times greater than any other terrestrial ecosystem, including boreal and tropical forests ${ }^{19}$. Peatlands also hold vast reservoirs of carbon ( $25 \%$ of world's carbon), but only cover $2-3 \%$ of terrestrial areas ${ }^{20}$. Meanwhile, natural grasslands harbour substantial carbon stores within their soil and can be more resilient than forests to drought and wildfires making them the more effective and secure carbon sink in the long term ${ }^{21}$. However, these important carbon stores barely feature in climate change policy. For example, while $42 \%$ of signatories to the Paris Agreement include in the mitigation components of their NDCs actions and targets for afforestation and/or restoration in terrestrial forest, only $19 \%$ do the same in coastal habitats.

Meanwhile, conservation actions in grasslands appear in only $11 \%$ of NDCs, montane habitats in only $4 \%^{2}$. Moreover, some of these important naturallytreeless habitats are threatened by afforestation, which is particularly troubling given that the original habitat can often provide greater carbon storage benefits $^{22}$.

In other words, we must not prioritise forest at the cost of continuing to destroy or replace other vitally important ecosystems. So let us be more inclusive when we discuss the importance of nature-based solutions to climate change and when we encourage policy makers to take them into account.

\section{Diverse ecosystems are also key to human adaptation}

In our drive to harness natural ecosystems to slow warming, we must not lose sight of their essential role in supporting human adaption. By prioritizing a variety of ecosystems and promoting their functional resilience to ensure reliable mitigation services, we will also secure the flow of a suite of ecosystem services vital for adaptation ${ }^{23}$. We know that natural habitats in watersheds can secure and regulate water supplies and protect communities from flooding and soil erosion; that mangroves, reefs and salt marshes protect us from storm surges, salt water intrusion and coastal erosion; and that agroforestry (planting trees among crops or crops within forest) can maintain and enhance yields in drier, more variable climates $^{24}$. Moreover, there are many economic benefits of these nature-based adaptation solutions through avoided losses to climate change related disasters. For example, coastal wetlands in northeast USA are estimated to provide USD 23.2 billion per year in storm protection services ${ }^{25}$, while annual damages from flooding would double and costs from frequent storms would triple in the absence of reefs globally ${ }^{26}$. In other words, restoring and protecting nature really isn't just about storing carbon and slowing warming, it's also about cost-effective protection of ecosystems to help shield us from floods, droughts, landslides, storms, heatwaves and other disasters increasingly common under climate change. Ultimately, it is about working with nature in such a way that ecosystems continue supporting human development and well-being in the face of change (Box 1). 


\section{Box 1: What are nature-based solutions?}

Nature-based Solutions (NbS) involve working with and enhancing nature to help address societal goals. They are "actions to protect, sustainably manage and restore natural or modified ecosystems, which address societal challenges (e.g. climate change, food and water security or natural disasters) effectively and adaptively, while providing human well-being and biodiversity benefits"3. They are also solutions "inspired and supported by nature, which are cost-effective, simultaneously provide environmental, social and economic benefits and help build resilience. Such solutions bring more, and more diverse, nature and natural features and processes into cities, landscapes and seascapes, through locally adapted, resource-efficient and systemic interventions"4. The concept of NbS has recently emerged against the backdrop of our failure to either stabilise the climate or stem the tide of biodiversity loss. However, high level pledges for "nature" tend to translate into targets for afforestation, often monocultures within single nonnative species, which will over the longterm produce maladaptation to climate change, compromise carbon storage and negatively impact on biodiversity and sustainable development in general.

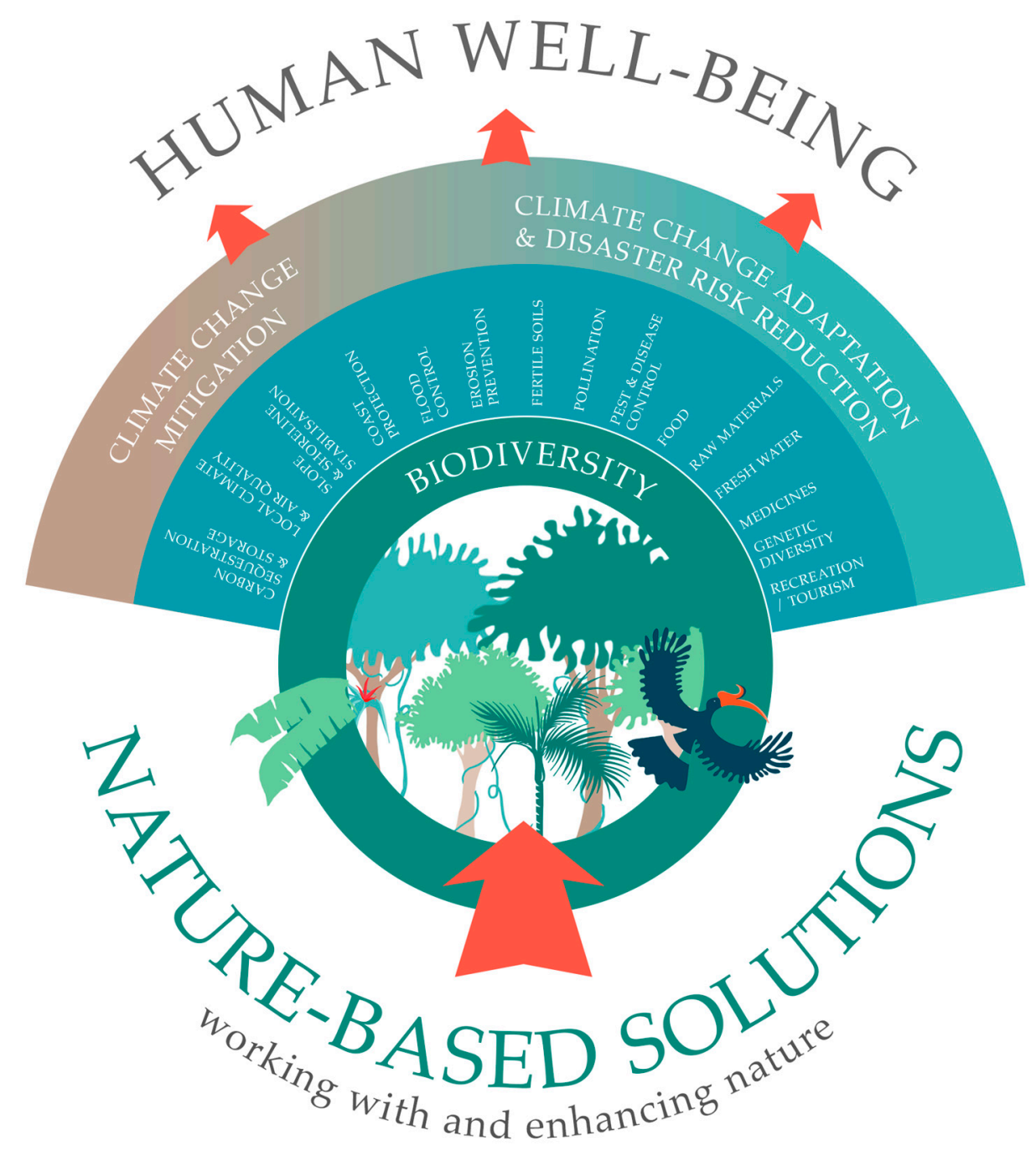




\section{Urgent need to integrate research and action on biodiversity and climate change}

All this highlights the need for much stronger links between the ecosystem science communities, especially ecologists, and those designing and implementing climate change policy. While the understanding of the role that biodiversity at all levels, including a diversity of habitats, can play in mitigating and adapting to climate change is growing rapidly, the policy areas for climate change and biodiversity remain largely separate. The result is a lack of robust targets for nature in climate pledges, beyond areas of forest to be planted or restored. As climate pledges get revised, we need to make sure that this knowledge is informing the process and helps raise ambition for nature. Examples of what can be achieved by this integrated approach are already emerging ${ }^{2}$.

\section{Biodiversity must be at the heart of the momentum for climate solutions}

We should celebrate the rapidly growing recognition of nature's importance in a warming world. We must welcome the fact that nature-based solutions were in the limelight at both United Nations Rio Convention Conferences last month and at the Global Climate Action Summit instigated by California governor Jerry Brown in September. However, as agendas for nature get translated into actions, let us not forget the importance of diverse intact natural ecosystems. In the fight against climate change, forests make excellent allies. However, unless we restore and protect a diversity of species-rich resilient ecosystems, guided by science and implemented through local stewardship, we cannot win the battle. We hope those advocating for action and funding at the UNFCCC meeting in Poland in December, will bear this in mind.

\section{References}

1. IPCC. Global warming of $1.5^{\circ} \mathrm{C}$. World Meteorological Organization, Geneva, Switzerland (2018)

2. Nature-based Solutions Policy Platform: www.nbspolicyplatform.org

3. Cohen-Shacham, E. et al. Gland, Switzerland: IUCN. xiii + 97pp. (2016)

4. European Commission: https://ec.europa.eu/research/enviro nment/index.cfm?pg=nbs

5. Dave, R. et al. Bonn Challenge Barometer of Progress: Spotlight Report 2017. (Gland, Switzerland: IUCN, 2017).

6. New York Declaration of Forests: http://forestdeclaration.org/ (2014)

7. Trillion Trees Partnership: https://www.trilliontrees.org/ (2018)

8. Le Quéré, C. et al. Earth Syst. Sci. Data 10, 405-448 (2018).

9. IUCN. Forest brief. No 21 (2017).

10. Watson, J. E. M. et al. Nat. Ecol. Evol 2, 599-610 (2018).

11. Lindner, M. et al. Forest Ecol. Manag. 259, 698-709 (2010).

12. Walker B, Holling CS, Carpenter SR \& Kinzig, A. Ecol. Soc. 9,5 (2004).

13. Oliver, T. H. et al. Trends Ecol Evol 30, 673-684 (2015).

14. Hutchinson, C. et al. Scientific Reports 8:15443 (2018)

15. Jactel, H. et al. Curr. For. Rep. 3, 223-243 (2017).

16. Sakschewski, B. et al. Nature Climate Change 6, 1032 (2016).

17. https://www.theforgottensolution.org/

18. Griscom, B. W. et al. PNAS 114, 11645-11650 (2017). 
19. Mcleod, E. et al. Front. Ecol. Environ. 9, 552-560 (2011).

20. Yu, Z. Biogeosciences 9, 40714085 (2012).

21. Dass, P. et al. Environ. Res. Lett 13, 074027 (2018).

22. Veldman, J. W. et al. BioScience 65, 1011-1018 (2015).
23. Lavorel, S. et al. Global Change Biol. 21, 12-31 (2014).

24. Jones, H. P. et al. Nat. Clim. Change 2, 504 (2012).

25. Constanza, R. et al. AMBIO 37, 241248 (2008)

26. Beck, M. et al. Nature

Communications 9, 2186 (2018).

\section{Box 2: Overview of the prominence of forests in climate policy}

Forest management for carbon stock enhancement was introduced in the context of the UN Framework Convention on Climate Change (UNFCCC) in 1992 and the concepts of afforestation and reforestation for climate change mitigation were first introduced in the Kyoto Protocol in 1997. The Bali Action Plan in 2007 brought the program on Reduced Emissions from Deforestation and land Degradation (REDD) to the negotiating table, with Forest Monitoring, Reporting, and Verification (MRV) under the UNFCCC reported as change in carbon stock over time. Parties rapidly realised that this metric leads to serious unintended consequences, and so the concept of "Safeguards" was introduced to the negotiating text in Cancun, 2010. Subsequent negotiations attempted to widen the scope of the framework to include non-carbon benefits linked to the social, environmental, and governance benefits of the five activities covered by REDD+. In the 2015 Paris Agreement, Parties are encouraged to adopt "...policy approaches and positive incentives for activities relating to reducing emissions from deforestation and forest degradation, and the role of conservation and sustainable management of forests and enhancement of forest carbon stocks in developing countries; and alternative policy approaches, such as joint mitigation and adaptation approaches for the integral and sustainable management of forests, while reaffirming the importance of incentivizing, as appropriate, non-carbon benefits associated with such approaches". In response, 49 signatories collectively pledged to restore 57 million hectares of forest in their Nationally Determined Contributions ${ }^{9}$. 